\title{
Female hormones fluctuation and chewing movement of patients with disc displacement
}

\section{Flutuação hormonal feminina e o movimento mastigatório de pacientes com deslocamento de disco}

\begin{abstract}
Purpose: This study aimed to verify the influence of hormonal fluctuations on chewing movement in women with disc displacement (DD).

Methods: Fourteen women with DD taking oral contraceptives $(\mathrm{OC})$; 12 DD-free controls taking OC; 12 normally cycling women with DD; and 14 DD-free normally cycling women were included. The Research Diagnostic Criteria for Temporomandibular Disorders diagnosed $\mathrm{DD}$, and subjects without pain were selected. Chewing movements were recorded using a kinesiograph. Dependent variables were: vertical, lateral, and anterior-posterior amplitudes $(\mathrm{mm})$, opening and closing velocity $(\mathrm{mm} / \mathrm{s})$, which was evaluated in 4 phases of 3 menstrual cycles, identified by ovulation test. Data were submitted to Mauchly's sphericity test, Proc Mixed for repeated measures, and Tukey-Kramer test $(P \leq 0.05)$.

Results: Comparisons among menstrual cycle phases showed no differences in vertical $(P=0.25)$, lateral $(P=0.12)$, and anterior-posterior amplitudes $(P=0.61)$; as well as opening $(P=0.57)$ or closing velocity $(P=0.73)$. The $O C$ use or presence of DD did not influence the variables $(P>0.05)$.

Conclusion: Hormonal fluctuation did not influence chewing mandibular movement of women with DD.
\end{abstract}

Key words: Mastication; jaw movements; temporomandibular joint disc; menstrual cycle

\section{Resumo}

Objetivo: Este estudo objetivou verificar a influência das flutuações hormonais nos movimentos mastigatórios de mulheres com deslocamento de disco (DD).

Metodologia: Foram selecionadas 14 mulheres com DD usuárias de contraceptivos orais (CO), 12 mulheres sem DD usuárias de OC (controle); 12 mulheres com DD e ciclos menstruais regulares e 14 mulheres sem DD e ciclos menstruais regulares. O Research Diagnostic Criteria para Desordens Temporomandibulares diagnosticou o DD, e voluntárias sem dor foram selecionadas. Os movimentos mastigatórios foram registrados usando um cinesiógrafo. Variáveis dependentes foram: amplitudes vertical, lateral e ântero-posterior $(\mathrm{mm})$, velocidade de abertura e fechamento $(\mathrm{mm} / \mathrm{s})$, sendo avaliadas nas 4 fases de 3 ciclos menstruais, identificado por teste ovulatório. Os dados foram submetidos ao teste de esfericidade de Mauchly, Proc Mixed para medidas repetidas e Tukey-Kramer $(P \leq 0,05)$.

Resultados: Comparações entre as fases do ciclo menstrual não mostraram diferenças nas amplitudes vertical $(P=0,25)$, lateral $(P=0,12)$, e ântero-posterior $(P=0,61)$, bem como na velocidade de abertura $(P=0,57)$ ou fechamento $(P=0,73)$. $\bigcirc$ uso $O C$ e a presença de $D D$ não influenciaram as variáveis $(P>0,05)$.

Conclusão: A flutuação hormonal não influenciou o movimento mandibular mastigatório de mulheres com DD.

Palavras-chave: Mastigação; movimentos mandibulares; disco da articulação temporomandibular; ciclo menstrual.

\author{
Jonas Alves de Oliveira ${ }^{a}$ \\ Thaís Marques Simek Vega Gonçalves ${ }^{a}$ \\ Larissa Soares Reis Vilanova ${ }^{\circ}$ \\ Glaucia Maria Bovi Ambrosano b \\ Renata Cunha M. Rodrigues Garcia a
}

\begin{abstract}
- Department of Prosthodontics and Periodontology, Piracicaba Dental School, State University of Campinas (UNICAMP), Piracicaba, SP, Brazil

b Department of Social Dentistry, Piracicaba Dental School, State University of Campinas (UNICAMP), Piracicaba, SP, Brazil
\end{abstract}

\section{Correspondence:}

Renata Cunha Matheus Rodrigues Garcia

Department of Prosthodontics and Periodontology Piracicaba Dental School, State University of Campinas Av. Limeira, $\mathrm{n}^{\circ} 901$

Piracicaba, SP - Brazil

$13414-903$

E-mail: regarcia@fop.unicamp.br

Received: February 2, 2012

Accepted: March 21, 2012

Conflict of Interests: The authors state that there are no financial and personal conflicts of interest that could have inappropriately influenced their work.

Copyright: (c) 2011 Oliveira et al.: licensee EDIPUCRS. This is an Open Access article distributed under the terms of the Creative Commons AttributionNoncommercial-No Derivative Works 3.0 Unported License. 


\section{Introduction}

Disc displacement (DD) is the most common form of temporomandibular joint disorder (TMD) (1) and could be defined as abnormal positions of the articular disc against the condyle and the temporomandibular joint (TMJ) articular eminence (2). Prior research has found that approximately $33 \%$ of asymptomatic subjects show some form of DD under magnetic resonance imaging (MRI) evaluation (3). These MRI images further reveal that anterolateral and anterior DD are the most frequent type of articular disc displacement, at least when the condyle is in the rest position $(2,3)$. Additional studies $(2,3)$ suggest that articular discs can be displaced in two different forms. In the first displacement, the disc remains displaced during the opening and closing movement, featuring DD without reduction. In the second displacement, the disc returns to the normal position during the opening movement but remains displaced during the closing movement, featuring DD with reduction. Acute or chronic trauma can contribute to either situation by causing elongation of the connective tissue attachments. Nonetheless, the displacements are frequently characterized by a "click" sound during the normal functional movement of the TMJ (4).

Patients with DD experience deviation or deflection of the jaw during the opening and closing movements (5), and this alteration may influence their chewing movement pattern, particularly in patients with non-reducing DD $(4,5)$. Several investigations (6-8) revealed the negative influence of TMD on the range of the mandibular movements, especially in patients experiencing TMD-related pain. According to Sato et al. (4), subjects with unilateral disc displacement without reduction presented impaired masticatory efficiency and deviated chewing movements in the TMJ-affectedchewing side. Additionally, Tsolka et al. (7) analyzed the mandibular movement from rest to intercuspal position and found that female TMD patients had significantly greater vertical and anterior-posterior range, as well as decreased lateral movement, compared to the 26 women and 2 men controls without any symptoms, signs or history of TMD. The restriction in lateral movements and greater range of motion of TMD patients could be related to mandibular movement impairment.

Women are more likely than men to develop and maintain TMD (9-11). In addition, TMD-related disturbances are more prevalent during a woman's reproductive years (10), which suggest a possible relationship between TMD and female hormonal fluctuations (11). Estrogen is likely involved in the pathogenesis of TMD (9-11). In fact, some reports (12-14) have shown that human skeletal muscle (13) contains alpha and beta estrogen receptors. Moreover, the synovial membrane, articular disc, and mandibular condyle also show high affinity for estrogen receptors $(11,14)$. According to Baltgalvis et al. (13), the responsiveness of the alpha estrogen receptor to circulating estrogen suggests that the hormone may influence TMJ development, restitution, and metabolism.
Considering that estrogen may influence collagen metabolism of the TMJ articular disc (15) and masticatory muscles, it is reasonable to hypothesize that hormonal fluctuations of the menstrual cycle may affect TMJ and chewing, which may then alter masticatory efficiency. Thus, the present study aimed to verify the influence of menstrual cycle hormonal fluctuations on chewing movement amplitude and velocity in women with asymptomatic DD.

\section{Material and methods}

Fifty-two female subjects, aged 17-43 years old, were selected to participate in this study. Subjects were chosen from students $(88.7 \%)$ and staff $(11.3 \%)$ at the Piracicaba Dental School, State University of Campinas. The Local Research Ethics Committee (\# 027/2008) approved the research protocol. All subjects were fully informed of the study purpose and signed the consent form for participation. To be included in our study, women had to present good general and oral health, complete dentition (except for missing third molars), and be free of malocclusion (anterior open bite, unilateral or bilateral posterior crossbite), facial deformities, and parafunctional habits (bruxism or tooth grinding). Women who were pregnant, menopausal, diagnosed with hormonal disease, treated with fertility drugs, or experiencing TMD-related pain symptoms were excluded from the study.

At the baseline appointment, all subjects were evaluated by the Research Diagnostic Criteria for Temporomandibular Disorders (RDC/TMD) (16). The RDC/TMD axis I was used for diagnosis of asymptomatic TMD patients, and those women presenting disk displacement with reduction (group IIa) were selected for the experimental group. Controls were selected according to the same criteria, without the presence of TMD. Then, subjects were divided into 4 groups according to the presence of DD and the intake of oral contraceptives (OC). Our final analyses included the following 4 groups: 14 women with DD taking OC (mean age $=23.3 \pm 4.1$ years); 12 DD-free controls taking OC (mean age $=23 \pm 2.9$ years); 12 normally cycling women with DD (mean age $=$ $23.9 \pm 5.3$ years) and 14 DD-free normally cycling women (mean age $=22.5 \pm 2.5$ years). Normally cycling women had regular menstrual cycles varying between 24-32 days and were free from $\mathrm{OC}$ usage for at least 3 months prior to the study. Women in the OC groups were taking a low dosage combination of exogenous sex hormone pills (estrogen and progesterone) in a 21-day cycle, and were on the pill-regime for at least 3 months prior to the study.

The menstrual cycle was divided into four phases (17-18), defining the last menses, ovulation period, and length of cycle as follows: (I) menstrual phase: Day 1 of bleeding to Day 5; (II) follicular phase: Day 6 to Day 11; (III) ovulatory phase: Day 12 to Day 16; and (IV) luteal phase: Day 24 to Day 28. In addition, subjects were instructed to contact the researcher on the first day of bleeding in order to establish time of the menstrual phase. Ovulation was verified by means of a BioEasy ovulation prediction test (BioEasy 
Diagnóstica, Belo Horizonte, Brazil). Women who were not taking OC's were shown how to use the ovulation prediction test to determine the ovulatory phase.

Mandibular movements during chewing were verified during each phase of three complete menstrual cycles. Importantly, at the time of evaluations and throughout the study, the researcher was blind to the RDC/TMD data. One researcher evaluated the four menstrual cycle phases at approximately the same time of day. Subjects taking OCs were evaluated on the corresponding days of the regular menstrual cycle period.

\section{Mandibular kinesiographic record}

A kinesiograph K6-I Evaluation System (MyotronicsNoromed Inc., Kent, WA, USA) recorded the jaw trajectory during mastication. Twenty cycles of habitual mandibular movements were evaluated during the mastication of a 17-cube-portion of artificial silicon test material Optosil ${ }^{\mathbb{B}}$ (Heraeus Kulzer, Sao Paulo, SP, Brazil). The kinesiograph equipment captured mandibular movement-produced graphic images, and IMAGE TOOL software (University of Texas Health Science Center, San Antonio, TX, USA) analyzed this data. The following movement variables were evaluated: vertical and lateral amplitude at the frontal plane $(\mathrm{mm})$, width anterior-posterior at the sagittal plane $(\mathrm{mm})$, and speed of opening and closing mandibular movements $(\mathrm{mm} / \mathrm{s})(5,19)$. Results were given as a mean of the 20 strokes analyzed.

Reproducibility of the vertical, lateral, and anteriorposterior amplitude, as well as opening and closing velocity, was verified by intraclass correlation coefficient (ICCs). Using a 95\% confidence level, we assessed these coefficients using two different measurements from 12 volunteers within a one-week time interval. The ICC ranged from 0.705 to 0.892, which was considered excellent (20).

\section{Statistical analysis}

All data were initially analyzed using Mauchly's sphericity test; however, sphericity was violated. Therefore, the SAS statistical program (SAS Institute Inc., Cary, NC, USA, Release 9.1, 2003), PROC MIXED procedure, was applied for repeated measures. Vertical, lateral, and anterior-posterior amplitude, and opening and closing velocity were dependent variables, while menstrual cycle phase and DD classification were the independent variables. Tukey-Kramer tests analyzed multiple comparisons among the groups and menstrual cycle phases at a significance level of $P=0.05$.

\section{Results}

Table 1 shows mean values for vertical, lateral, and anterior-posterior amplitudes of the masticatory cycle (mm). Irrespective of hormonal fluctuation, DD subjects and matched controls failed to show differences between variables $(P>0.05)$. There was also no significant difference detected between women with and without OCs on vertical $(P=0.82)$, lateral $(P=0.15)$, and anterior-posterior $(P=0.70)$ amplitudes. Similarly, comparisons among menstrual cycle phases showed no differences in the three amplitudes studied ( $P=0.25 ; P=0.12 ; P=0.61$; respectively) for all groups.

Table 2 exhibits a similar trend, showing no differences in the mean value of opening and closing velocity between the DD and control groups $(P>0.05)$. During chewing movements, opening $(P=0.57)$ and closing $(P=0.73)$ velocity failed to significantly differ across the menstrual cycle phases, and the use of OCs also did not influence these movements ( $P=0.60 ; P=0.84$; respectively).

Table 1. Mean values and standard deviations for vertical, lateral, and anterior-posterior amplitudes of the masticatory cycle (mm).

\begin{tabular}{ccccccc}
\hline & \multicolumn{2}{c}{ Vertical Amplitude } & \multicolumn{2}{c}{ Lateral Amplitude } & \multicolumn{2}{c}{ Anterior-Posterior Amplitude } \\
\hline & With DD & Without DD & With DD & Without DD & With DD & Without DD \\
\hline Not Taking OC & & & & & & \\
Menstrual & $22.61( \pm 2.75)$ & $21.42( \pm 3.02)$ & $16.89( \pm 3.22)$ & $17.29( \pm 4.88)$ & $9.64( \pm 2.25)$ & $9.10( \pm 2.00)$ \\
Follicular & $23.03( \pm 3.00)$ & $22.00( \pm 3.28)$ & $16.65( \pm 3.46)$ & $17.57( \pm 4.46)$ & $9.77( \pm 2.37)$ & $8.76( \pm 2.19)$ \\
Ovulatory & $23.32( \pm 2.90)$ & $21.85( \pm 3.36)$ & $16.65( \pm 3.31)$ & $17.32( \pm 4.85)$ & $9.43( \pm 2.23)$ & $9.20( \pm 1.88)$ \\
Luteal & $22.82( \pm 3.16)$ & $22.03( \pm 3.06)$ & $17.31( \pm 3.72)$ & $17.47( \pm 4.33)$ & $9.82( \pm 1.92)$ & $8.74( \pm 1.43)$ \\
Taking OC & & & & & & \\
Bleeding period & $21.92( \pm 3.08)$ & $23.09( \pm 2.55)$ & $19.06( \pm 4.54)$ & $17.98( \pm 3.43)$ & $8.96( \pm 1.89)$ & $9.57( \pm 2.06)$ \\
$2^{\text {nd }}$ Assessment & $22.04( \pm 3.18)$ & $22.59( \pm 3.15)$ & $18.70( \pm 3.61)$ & $18.21( \pm 3.24)$ & $9.33( \pm 1.72)$ & $9.57( \pm 1.76)$ \\
$3^{\text {rd }}$ Assessment & $22.11( \pm 3.67)$ & $22.97( \pm 2.47)$ & $18.47( \pm 3.99)$ & $18.78( \pm 3.55)$ & $9.38( \pm 1.84)$ & $9.68( \pm 2.06)$ \\
$4^{\text {th }}$ Assessment & $22.90( \pm 3.03)$ & $22.96( \pm 3.09)$ & $19.03( \pm 3.50)$ & $18.21( \pm 3.24)$ & $9.76( \pm 1.66)$ & $9.58( \pm 2.34)$ \\
Mean & $22.59( \pm 3.10) \mathrm{A}$ & $22.36( \pm 3.00) \mathrm{A}$ & $17.85( \pm 3.67) \mathrm{A}$ & $17.85( \pm 4.00) \mathrm{A}$ & $9.51( \pm 1.99) \mathrm{A}$ & $9.28( \pm 1.97) \mathrm{A}$ \\
\hline
\end{tabular}

$\mathrm{DD}=$ Disc displacement; $\mathrm{OC}=$ Oral contraceptive

Means followed by the same letter are not statistically different $(P>0.05)$ 
Table 2. Mean values and standard deviations for opening and closing velocity of the masticatory cycle ( $\mathrm{mm} / \mathrm{s})$ according to DD and $\mathrm{OC}$ condition and period of evaluation.

\begin{tabular}{|c|c|c|c|c|}
\hline & \multicolumn{2}{|c|}{ Opening Velocity } & \multicolumn{2}{|c|}{ Closing Velocity } \\
\hline & With DD & Without DD & With DD & Without DD \\
\hline \multicolumn{5}{|l|}{ Not Taking $O C$} \\
\hline Menstrual & $9.01( \pm 2.34)$ & $8.54( \pm 1.86)$ & $6.79( \pm 1.02)$ & $7.13( \pm 1.22)$ \\
\hline Follicular & $8.93( \pm 2.55)$ & $8.59( \pm 1.32)$ & $6.76( \pm 1.29)$ & $7.07( \pm 0.98)$ \\
\hline Ovulatory & $8.98( \pm 2.09)$ & $8.28( \pm 1.76)$ & $6.94( \pm 0.96)$ & $6.96( \pm 1.28)$ \\
\hline Luteal & $9.37( \pm 2.88)$ & $8.12( \pm 1.78)$ & $7.17( \pm 1.17)$ & $6.70( \pm 1.15)$ \\
\hline \multicolumn{5}{|l|}{ Taking $O C$} \\
\hline Bleeding period & $8.23( \pm 3.12)$ & $8.32( \pm 2.36)$ & $6.60( \pm 1.85)$ & $6.98( \pm 1.49)$ \\
\hline $2^{\text {nd }}$ Assessment & $8.56( \pm 3.61)$ & $8.70( \pm 2.43)$ & $6.66( \pm 1.80)$ & $7.07( \pm 1.60)$ \\
\hline $3^{\text {rd }}$ Assessment & $8.44( \pm 2.86)$ & $9.28( \pm 2.82)$ & $6.58( \pm 1.75)$ & $7.40( \pm 1.65)$ \\
\hline $4^{\text {th }}$ Assessment & $8.56( \pm 3.01)$ & $8.34( \pm 2.17)$ & $6.65( \pm 1.69)$ & $6.96( \pm 1.65)$ \\
\hline Mean & $8.76( \pm 2.81) \mathrm{A}$ & $8.52( \pm 2.06) \mathrm{A}$ & $6.77( \pm 1.44) \mathrm{A}$ & $7.03( \pm 1.38) \mathrm{A}$ \\
\hline
\end{tabular}

DD = Disc displacement; $\mathrm{OC}=$ Oral contraceptive

Means followed by the same letter are not statistically different $(P>0.05)$

\section{Discussion}

Prior studies have shown a decrease in the excursive range of mandibular motion in TMD subjects $(6,8,21)$, and data show that women are more susceptible to $\operatorname{TMD}(10,11)$. Although, several records $(12,13,22)$ have analyzed the relationship between female hormones on muscle activity and joint ligament laxity (17), the influence of hormonal fluctuation on chewing movements in asymptomatic DD women had never been evaluated. Despite such evaluation could contribute to guide a specific and differential treatment for this population, the current study failed to detect differences in chewing movements across the menstrual cycles of women with or without asymptomatic DD. This finding is consistent with Gonçalves et al. (18), who reported no differences between menstrual cycle phases and maximum occlusal force or masticatory performance. These variables represent important predictors of masticatory function, as well as the chewing movement (23). Thus, since masticatory performance is not influenced by the variation in female hormones, it is not surprising that our results showed that chewing movements were also not affected by hormone levels.

Although gender and age of TMD patients suggest a possible link between its pathogenesis and the female reproductive system $(9,11)$, it seems that the presence of estrogen may exert a stronger influence on TMD compared to the hormone's cyclic variations across the menstrual cycle $(14,15)$. Furthermore, estrogen is related to TMD pain modulation (11), such that normally cycling women experience increased pain during the days following ovulation and in the menstrual phase, in concurrence with a marked decline in estrogen levels (10). It is also known that pain decreases agonist muscle activity, and increases antagonist

activity, an imbalance that may alter the range of mandibular motion and velocity as part of a normal protective adaptation process (24). This alteration in muscle activity could result in mandibular movement impairment. Importantly, the present study excluded subjects with pain in order to avoid these potential confounding variables. Thus, additional research is needed to confirm whether female hormone levels would affect mandibular movements in TMD patients with pain.

Regardless of the pain-free sample, we expected that DD subjects would show chewing movement impairment because the displaced articular disc would act as a mechanical interference to alter mandibular movement; however, we did not observe this finding. The results of this study compliment Hirsch et al. (25), whom reported no differences in the range of motion between TMD asymptomatic adolescents and healthy controls. In contrast, several other studies have shown limitations on maximum excursions in TMD patients $(5-8,21)$. However, as suggested by Sinn et al. (8), it should be noted that when mandibular movement is evaluated during the mastication process, limitations are similar between patients and controls $(6,8)$. For example, TMD patients and controls display similar maximum incisal opening during mastication $(16.21 \mathrm{~mm}$ and $18.03 \mathrm{~mm}$, respectively) (8). Furthermore, a kinesiographic evaluation of TMD patients performed by Sato et al. (6) showed that the chewing pattern of patients, prior to their DD without reduction treatment, was not significantly different from that of normal controls. Moreover, according to Célic et al. (21) is not possible to guarantee that the measurements of active mandibular movements can discriminate TMD patients from asymptomatic subjects. Taken together, these studies suggest that differences in chewing movements of TMD patients and controls do not exist since the mean ranges of the active movements were clinically normal in both groups $(6,8,21)$. 


\section{Conclusions}

The results of the present study are important because they contribute to clinical management and decision-making of DD patients. Since differences were not detected between chewing movement variables in pain-free DD patients and controls, it may be suggested that there is a TMJ adaptation process in the dynamics of chewing movements (21), and that those movements become similar between subjects with and without DD $(6,8)$. Moreover, our findings demonstrate that mandibular movement during mastication was unaffected by hormonal fluctuations in women with pain- free DD. Therefore, the results of the present study enhance understanding of the relationship between asymptomatic DD and chewing movement in women, and suggest that monitoring signs and symptoms of TMD may be more important than clinical intervention for such patients.

\section{Acknowledgments}

This study was supported by the Fundação de Amparo à Pesquisa do Estado de São Paulo (FAPESP), grant no. 2008/03106-6, and Fundação de Amparo à Pesquisa do Estado do Amazonas (FAPEAM), grant no. 2009/053, Brazil. of temporomandibular joint disk displacement in patients and symptom-free volunteers. Am J Orthod Dentofacial Orthop 1996;109:249-62.

2. Katzberg RW, Westesson PL, Tallents RH, Drake CM. Anatomic disorders of the temporomandibular joint disc in asymptomatic subjects. J Oral Maxillofac Surg 1996; 54:147-53.

3. Bisil MA, Chaves KDB, Puricelli E, Ponzoni D, Martins EA. Relationship between sounds and disc displacement of the temporomandibular joint using magnetic resonance imaging. Rev Odonto Ciênc 2010;25:37-41.

4. Sato S, Goto S, Takanezama H, Kawamura H, Motegi K. Electromyographic and kinesiographic study in patients with nonreducing disk displacement of the temporomandibular joint. Oral Surg Oral Med Oral Pathol Oral Radiol Endod 1996;81:516-21.

5. Nielsen IL, Marcel T, Chun D, Miller AJ. Patterns of mandibular movements in subjects with craniomandibular disorders. J Prosthet Dent 1990;63:202-17.

6. Sato S, Nasu F, Motegi K. Analysis of kinesiograph recordings and masticatory efficiency after treatment of non-reducing disk displacement of the temporomandibular joint. J Oral Rehabil 2003;30:708-13.

7. Tsolka P, Walter JD, Wilson RF, Preiskel HW. Occlusal variables, bruxism and temporomandibular disorders: a clinical and kinesiographic assessment. J Oral Rehabil 1995;22:849-56.

8. Sinn DP, De Assis EA, Throckmorton GS. Mandibular excursions and maximum bite forces in patients with temporomandibular joint disorders. J Oral Maxillofac Surg 1996;54:671-9.

9. Warren MP, Fried JL. Temporomandibular disorders and hormones in women. Cells Tissues Organs $2001 ; 169: 187-92$

10. LeResche L, Mancl L, Shermann JJ, Gandara B, Dworkin SF. Changes in temporomandibular pain and other symptoms across the menstrual cycle. Pain 2003;106:253-61.

11. Wang J, Chao Y, Wan Q, Zhu Z. The possible role of estrogen in the incidence of temporomandibular disorders. Med Hypotheses 2008;71:564-7.

12. Janse de Jonge XA, Boot CR, Thom JM, Ruell PA, Thompson MW. The influence of menstrual cycle phase on skeletal muscle contractile characteristics in humans. J Physiol 2001;530:161-6.

13. Baltgalvis KA, Greising SM, Warren GL, Lowe DA. Estrogen regulates estrogen receptors and antioxidant gene expression in mouse skeletal muscle. PLoS One 2010;13:e10164.

14. Abubaker AO, Raslan WF, Sotereanos GC. Estrogen and progesterone receptors in temporomandibular joint discs of symptomatic and asymptomatic persons: A preliminary study. J Oral Maxillofac Surg 1993;51:1096-100.

15. Gage JP. Mechanisms of disc displacement in the temporomandibular joint. Aust Dent J 1989;34:427-36

16. Dworkin SF, LeResche L. Research diagnostic criteria for temporomandibular disorders: review, criteria, examinations and specifications, critique. J Craniomandib Disord 1992;6:301-55.

17. Karageanes SJ, Blackburn K, Vangelos ZA. The association of the menstrual cycle with the laxity of the anterior cruciate ligament in adolescent female athletes. Clin J Sport Med $2000 ; 10: 162-8$

18. Gonçalves TMSV, Sanchez-Ayala A, Ambrosano GMB, Rodrigues Garcia RCM. Female hormonal fluctuation and masticatory function in patients with disc displacement-a casecontrol study. Int J Prosthodont 2011 ;24:320-7. 
19. Barciela Castro N, Fernandez Varela JM, Martin Biedma B, Rilo Pousa B, Suarez Quintanilla J, Gonzalez Bahillo J, et al. Analysis of the area and length of masticatory cycles in male and female subjects. J Oral Rehabil 2002;29:1160-4.

20. Szklo M, Nieto FJ. Epidemiology beyond the basics, 2sd ed. Gaithersburg: Maryland, 2006.

21. Célic R, Jerolimov V, Knezovic Zlataric D, Klaic B. Measurement of mandibular movements in patients with temporomandibular disorders and in asymptomatic subjects. Coll Antropol 2003;27:43-9.

22. Coyne C. Muscle tension and its relation to symptoms in the premenstruum. Res Nurs Health 1983;6:199-205.

23. Ow RKK, Carlsson GE, Karlsson S. Relationship of masticatory mandibular movements to masticatory performance of dentate adults: a method study. J Oral Rehabil 1998;25:821-9.

24. Lund JP, Donga R, Widmer CG, Svensson P. Reduction adaptation model: a discussion of the relationship between chronic musculoskeletal pain and motor activity. Can J Physiol Pharmacol 1991;69:683-94.

25. Hirsch C, John MT, Lautenschlager C, List T. Mandibular jaw movement capacity in 10 17-yr-old children and adolescents: normative values and the influence of gender, age, and temporomandibular disorders. Eur J Oral Sci 2006;1 14:465-70. 